\title{
A arte de MOMÓ
}

\section{The art of MOMÓ}

TENÓRIO, Thalyne; Bacharel; Universidade do Estado do Pará

thalyne.chrystyna@gmail.com

RODRIGUES, Manoel Alacy da Silva; Mestre; Universidade do Estado do Pará

alacy.rodrigues@gmail.com

\section{Resumo}

Este projeto buscou aplicar a metodologia de design ao processo criativo de um curta de animação inspirado no cenário da cidade de Belém-PA, com o objetivo de fomentar a área na região; promovendo a cultura belenense. As metodologias utilizadas foram: pesquisa de campo, registros fotográficos, documentação direta (observação mais especificamente), e questionário online, e a partir disso foram extraídos elementos representacionais da cidade (com o que as pessoas mais se identificam), foi também realizada uma pesquisa bibliográfica e documental para fundamentar a relação da animação com o design. Os objetivos propostos foram a elaboração de um briefing e painel semântico (coletando os elementos mais significativos da cidade), a partir dos dados recolhidos, e a produção do storyboard, concept art, e a animação em si, com auxílio do software Toon Boom Harmony. Todos os objetivos foram satisfatoriamente alcançados, e originaram o curta de animação "Momó".

Palavras Chave: Design. Animação. Concept art. Belém.

\section{Abstract}

This project sought to apply the design methodology to the creative process of an animated short inspired by the scenario of Belém-PA, with the aim of promoting the area in the region; promoving belenense culture. The methodologies used were: field research, photographic records, direct documentation (observation more specifically), and online questionnaire, and from that were extracted representative elements of the city (with which people identify the most), a bibliographical and documentary research was also carried out to substantiate the relationship between animation and design. The proposed objectives were the elaboration of a briefing and semantic panel (collecting the most significant elements of the city), resulted of the collected data, and the production of storyboard, concept art, and the animation itself, using the software Toon Boom Harmony. All the objectives were satisfactorily achieved, and gave rise to the animated short film "Momó".

Keywords: Design. Animation. Concept art. Belem. 


\section{Introdução}

O design é uma extensa área de conhecimento, e pode ser utilizado como uma ferramenta integradora, conectando diversas atividades e profissionais, e otimizando processos. Portanto, não é de se estranhar que possa ser amplamente utilizado na concepção de produtos audiovisuais, em especial animações.

Animação atrai a atenção não apenas de crianças, mas de todas as faixas etárias, podendo ser desde os desenhos animados mais tradicionais, aos famosos $3 d^{\prime}$ 's atuais. Para se chegar a esses produtos finais, prontos para serem consumidos, é necessário antes passar por uma cadeia de produção que exige uma preparação conceitual e imagética que norteará toda a produção. Nesta etapa, as ferramentas do design podem ser extremamente úteis.

No Brasil, as animações vêm ganhando cada vez mais espaço, e com esse crescente mercado significa que tem havido uma maior procura por produtos de animação, e, portanto, por profissionais que possam construí-los. No Pará, a animação também vem se desenvolvendo gradativamente, e vêm apresentando ótimos resultados, contudo, considerando-se outros estados do país, ainda há muito a avançar. Somando-se a isso, Belém-Pará, oferece um rico cenário, cheio de belezas naturais, costumes únicos, folclore rico, que podem ser utilizados de diversas maneiras para compor uma animação.

Desse modo, foi aplicada a metodologia do Design (mais especificamente a de Munari, 1981) na produção de um curta de animação, utilizando o cenário atual de Belém - Pará. Os objetivos estabelecidos foram a realização de pesquisas bibliográficas sobre conceitos de animação e design, aplicação de questionários online, para a execução do briefing, realização de um levantamento fotográfico e iconográfico da cidade, visando a definição do conceito do curta de animação, e a partir disso, a formulação do roteiro, para o curta de animação; criação dos concepts arts dos cenários e personagens, colorscripts, e dos storyboards para o desenvolvimento da animação.

Para a realização da pesquisa, as metodologias aplicadas foram, quanto aos objetivos, a pesquisa explicativa, a qual, segundo Gil (2002), buscaria explicar a razão, o porquê das coisas. A fundamentação deste trabalho foi dada com base na identificação das principais manifestações culturais de Belém-PA, bem como a relação de identidade dos moradores, os ícones que representam a cidade, etc. Os procedimentos técnicos foram, pesquisa bibliográfica, pesquisa documental (utilizando-se matérias de jornais), e a observação, que segundo Marconi e Lakatos (2003): "utiliza os sentidos na obtenção de determinados aspectos da realidade. Não consiste apenas em ver e ouvir, mas também em examinar fatos ou fenômenos que se deseja estudar" ( $p$. 190). Outra técnica utilizada foi a pesquisa participante, que "caracteriza-se pela interação entre pesquisadores e membros das situações investigadas. [...] envolve a distinção entre ciência popular e ciência dominante".

Os instrumentos de coleta foram: câmera fotográfica, questionário, além de softwares como Toon Boom Harmony 14, pacote Adobe, lápis grafite e aquarela. 


\section{A arte de MOMÓ}

Primeiramente, para se desenvolver o curta de animação, foi necessário realizar uma coleta e análise de dados sobre a cidade, para assim identificar os pontos mais representativos da mesma. A pesquisa foi orientada pela metodologia de Munari (1998), associada àquela proposta por Seegmiller (2008), como mostra o quadro 1.

Quadro 1: Passos da metodologia de Munari (1998) e Seegmiller (2008) relacionadas.

\begin{tabular}{|c|c|c|}
\hline MUNARI (1998) & SEEGMILLER (2008) & \\
\hline $\begin{array}{l}1 \text { - Problema } \\
2 \text { - Definição }\end{array}$ & $\begin{array}{l}\text { 1- Identificando e } \\
\text { entendendo o } \\
\text { problema. }\end{array}$ & \\
\hline $\begin{array}{l}3 \text { - Componentes do } \\
\text { problema; } \\
4 \text { - Coleta de dados; } \\
\text { 5- Análise dos dados. }\end{array}$ & $\begin{array}{l}2 \text { - Analisando o } \\
\text { problema e } \\
\text { quebrando-o em } \\
\text { pequenas partes. }\end{array}$ & \\
\hline $\begin{array}{l}6 \text { - Criatividade; } \\
7 \text { - Materiais e } \\
\text { tecnologia; } \\
8 \text { - Experimentação. }\end{array}$ & $\begin{array}{l}2 \text { - Melhores ideias } \\
\text { para resolver o } \\
\text { problema; } \\
3 \text { - Escolhendo a } \\
\text { melhor ideia. }\end{array}$ & $\begin{array}{l}\text { Com a coleta e análise dos dados, junta- } \\
\text { mente com auxílio de ferramentas de } \\
\text { criatividade, utilizando-se dos materiais } \\
\text { mais convenientes, serão geradas possi- } \\
\text { veis soluções - ideias; } \\
\text { Qual ideia melhor convém para a solução } \\
\text { do problema? }\end{array}$ \\
\hline $\begin{array}{l}9 \text { - Modelo; } \\
10 \text { - Verificação; } \\
11 \text { - Desenho de } \\
\text { construção. }\end{array}$ & $\begin{array}{l}4 \text { - Desenhando a } \\
\text { personagem; } \\
5 \text { - Analisando os } \\
\text { resultados. }\end{array}$ & $\begin{array}{l}\text { Construção da representação final } \\
\text { dos concepts. }\end{array}$ \\
\hline
\end{tabular}

Fonte: A autora (2017).

A única etapa não realizada foi a verificação, que está em branco no quadro 1.

\subsection{Problema/ Definição - Identificando e entendendo o problema}

O problema definido foi o seguinte: "O mercado - produção e consumo - ainda reduzido de produtos relacionados a concept art e audiovisuais, na cidade de Belém-PA., que tenham como enfoque a mesma". A partir deste, retirou-se como pontos centrais a produção de concept arts que traduzissem e comunicassem Belém-PA, e a tradução da história e palavras, para uma imagética, no storyboard. 


\subsection{Componentes do problema, Coleta de dados, Análise dos dados;}

\section{- Analisando o problema e quebrando-a em pequenas partes.}

Nesta fase, o problema foi subdividido em problemas menores a serem resolvidos, os quais foram analisados para a geração de ideias.

Os subproblemas gerados foram: Quais são os elementos mais icônicos do cenário? Quais são as cores mais recorrentes no cenário? Quais são os elementos mais simbólicos típicos do cenário? Qual é a temática que mais chama a atenção no momento? Quais são as características mais apreciadas pelos turistas e pelos próprios residentes? Quais são as formas mais recorrentes no cenário? De que forma pode-se fazer a animação no tempo hábil disponível?

\subsubsection{Questionário online}

Com o auxílio da ferramenta "formulário", disponível no Google, foi realizada uma pesquisa quantitativa acerca do que mais remete, as pessoas, à cidade de Belém, bem como o que elas consideram que mais representa a cidade.

Ao todo, 135 pessoas responderam ao questionário, na primeira pergunta "O que mais lembra Belém para você?", foram dadas as seguintes opções: Culinária, Ver-o-Peso, outros pontos turísticos, clima (sol/ chuva), açaí, população (comportamento), mangueiras, e outros. Segundo a imagem 1, a maioria das pessoas se lembra da cidade pela sua culinária, em seguida, o mais marcante foi o ponto turístico Ver-o-Peso, e depois o clima (sol/ chuva).

Figura 1: Gráfico I resultante do questionário aplicado

\section{O que mais lembra Belém para você?}

135 respostas
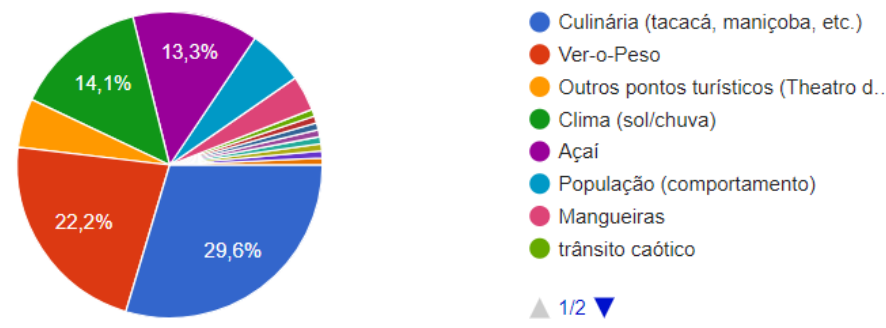

Fonte: A autora (2017).

Quanto à segunda pergunta, referente ao que a pessoa considera como uma "lembrança para pessoas que moram fora da cidade". As opções dadas foram: Açaí, bombons regionais, Muiraquitã, alguma peça de cerâmica, tucupi e jambú, e outros. Segundo a imagem 2, percebe-se que a culinária também foi o mais votado, com açaí em primeiro lugar, seguido de bombons regionais, e depois, saindo da área culinária, o Muiraquitã, um amuleto indígena associado à fertilidade e à boa sorte. 
Figura 2: Gráfico II resultante do questionário aplicado

O que você costuma levar de lembrança para pessoas que moram fora da cidade?

134 respostas
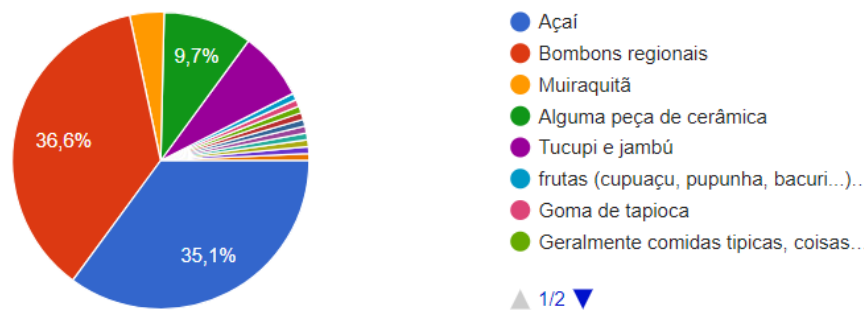

Fonte: A autora (2017).

Foram adicionadas, como respostas, as opções "frutas", "goma de tapioca" e "comidas típicas", "cachaça de jambú" e "farinha". Percebe-se, portanto, que mais de 50\% das opções são relacionadas à culinária.

Para utilizar como fonte imagética - portanto, fonte de cores, formas, texturas, etc. - foi construído um painel semântico, que resume o que foi coletado na pesquisa anterior. A figura 3 foi o resultado obtido.

Figura 3: Painel semântico "Belém", resultado do questionário.

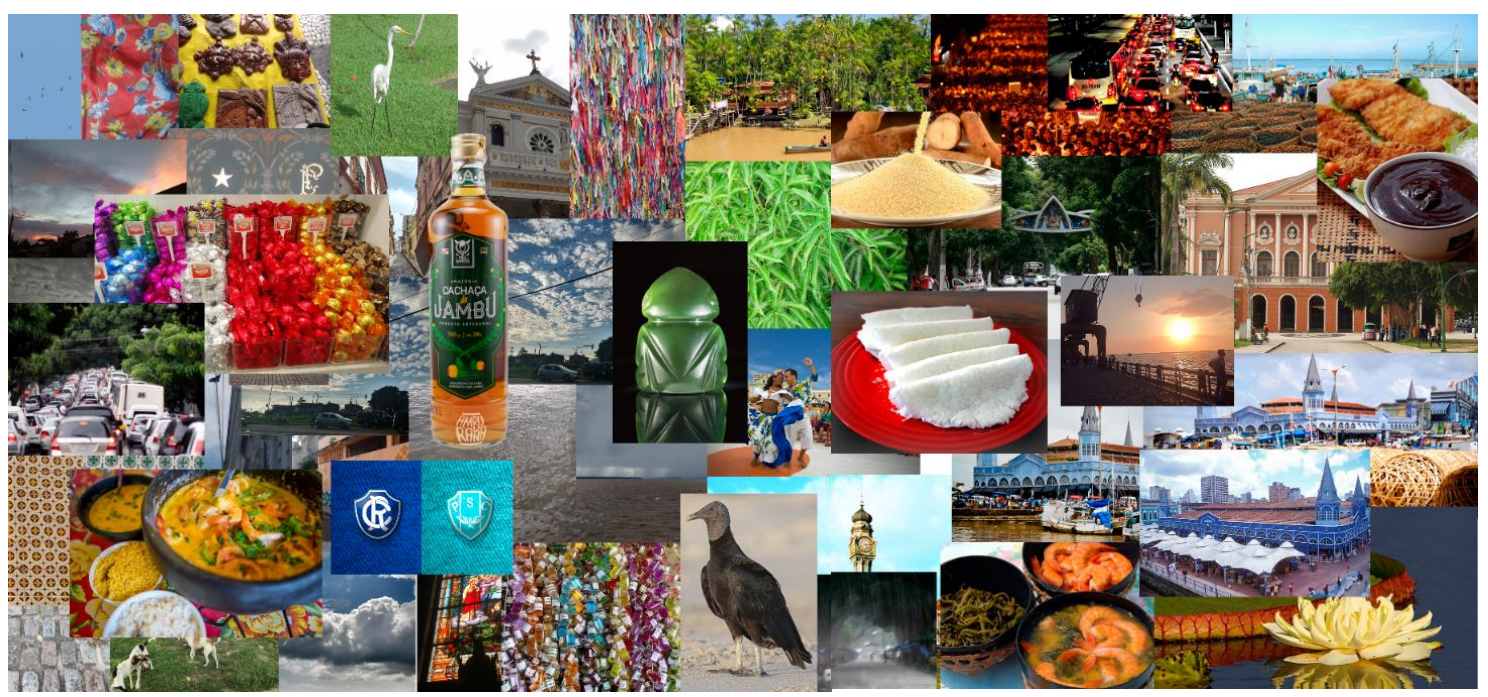

Fonte: A autora (2017).

Com base nesse painel, foi gerada uma paleta de cores (imagem 4). 
Figura 4: Paleta de cores.

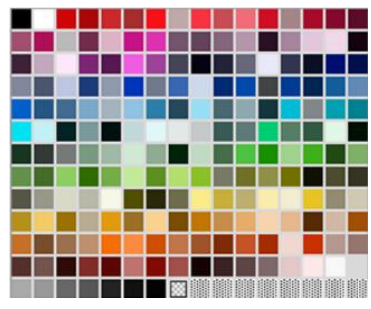

Fonte: A autora (2017).

Como resultado tem se a presença de tons de azul e vermelho/ laranja, fora alguns tons de verde e amarelo. A paleta de cores mostrou-se com tons naturais (azul-céu; vermelho/ laranja-terra; verde-plantas; amarelo-sol).

\subsection{Criatividade; Materiais e Tecnologia, Experimentação.}

\section{- Melhores ideias para resolver o problema}

Nesta etapa foram desenvolvidos, utilizando as informações coletadas, o roteiro, concepts, storyboard, tudo que foi utilizado para o curta. Com relação ao material especificamente, não se teve preferência por nenhum, mas experimentou-se aquarela, lápis de cor, grafite, papel e ferramentas digitais, com auxílio da mesa digitalizadora Wacom, buscando experimentar estéticas diferentes.

\subsubsection{Roteiro}

Com base nos dados apresentados nas figuras 1 e 2, percebeu-se que a preferência, com relação à identidade da cidade, foi a gastronomia paraense, portanto, foi este assunto que foi abordado no curta. Para se chegar ao roteiro final, foi utilizado alguns recursos, como o "E se" (what if?), que segundo Beiman (2013, p. 58) é considerar coisas que poderiam possivelmente acontecer com as personagens e com a história. Desse modo, pode se começar com um roteiro simples, e ir aos poucos desenvolvendo suas possibilidades, e transformá-lo em algo não usual.E se a nossa Momó (modo de chamar a preguiça e letargia sentida após o almoço, principalmente quando este acompanhado com açaí) ganhasse vida?

O curta tem início com uma visão geral do local, no qual mostra a personagem que aparenta estar perdida. Ela encontra um bichinho -Momó- desconhecido e se aproxima dele, eles se tocam e o bichinho corre e se esconde. A personagem principal corre atrás da Momó, e quando a encontra ela, está muito maior e assustadora, entretanto, a Momó tenta fazer contato com a personagem tal qual elas fizeram anteriormente, a personagem principal, mesmo que receosa, estende o braço. Por um momento parece que tudo está bem, até que a Momó a puxa e "engole", após isso, a personagem acorda, e se vê sentada em frente a uma mesa com um prato e uma tigela de açaí vazios, ela se espreguiça, e satisfeita, volta a dormir.

\subsubsection{Storyboard}


O storyboard é uma parte fundamental da concepção de uma animação, segundo Beiman (2013):

O storyboard de animação cria as personagens junto com as configurações. O storyboard é o desempenho do ator de animação. Cada parte do filme é planejada no storyboard desenhos de personagens, atuação, ação, ritmo, história, diálogo, efeitos, movimentos da câmera e edição. Filmes animados são direcionados pelo storyboard ${ }^{1}$ (BEIMAN, 2013, p. 18)

Para o curta "MOMÓ", o storyboard passou por três tratamentos, passando originalmente de 66 quadros, para 40 quadros. Ainda no primeiro storyboard, há um enfoque nas "comidas contrárias ao açaí", como a banana, e surgiu a presença da farinha como complemento do açaí. Passando para o segundo storyboard feito, foram retiradas outras ideias, como o pato como referência à comida típica do período do Círio, e a presença de um urubu e uma garça, animais muito presentes no Ver-o-Peso.

Figura 5: Elementos dos primeiros tratamentos do storyboard
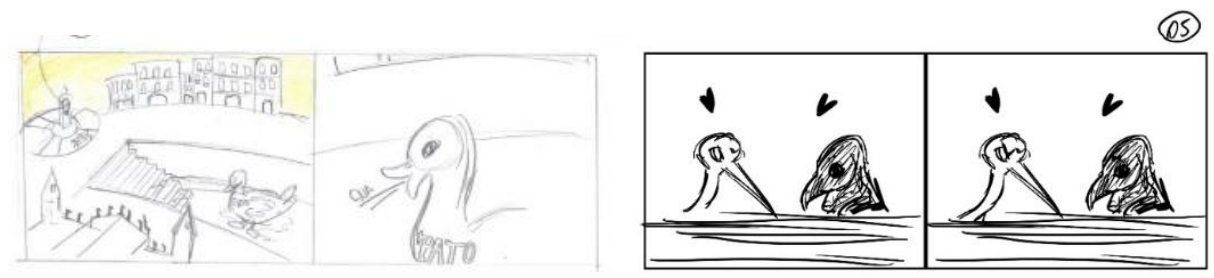

Fonte: A autora (2017).

Por fim, chegou-se à versão final do storyboard (figura 6).

Figura 6: Versão final do storyboard.

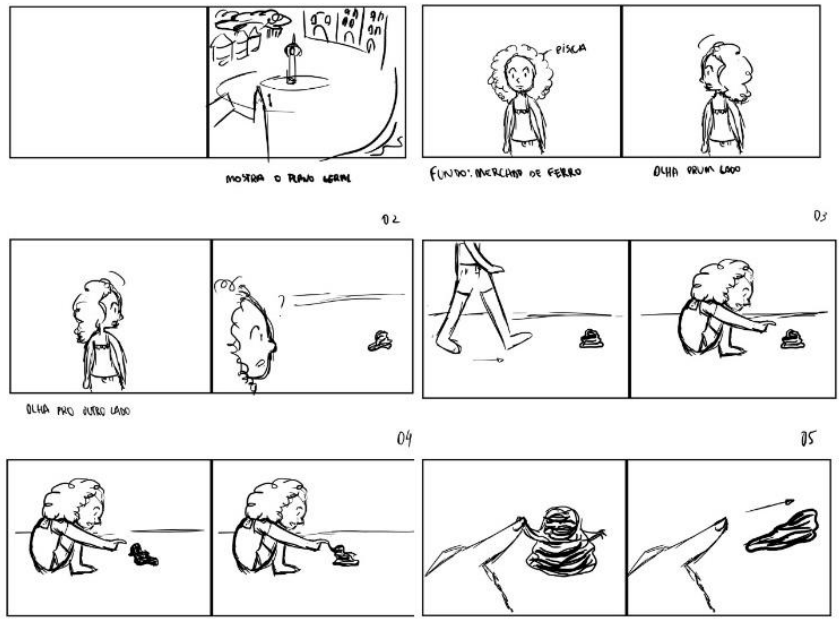

\footnotetext{
1 Tradução da autora
} 

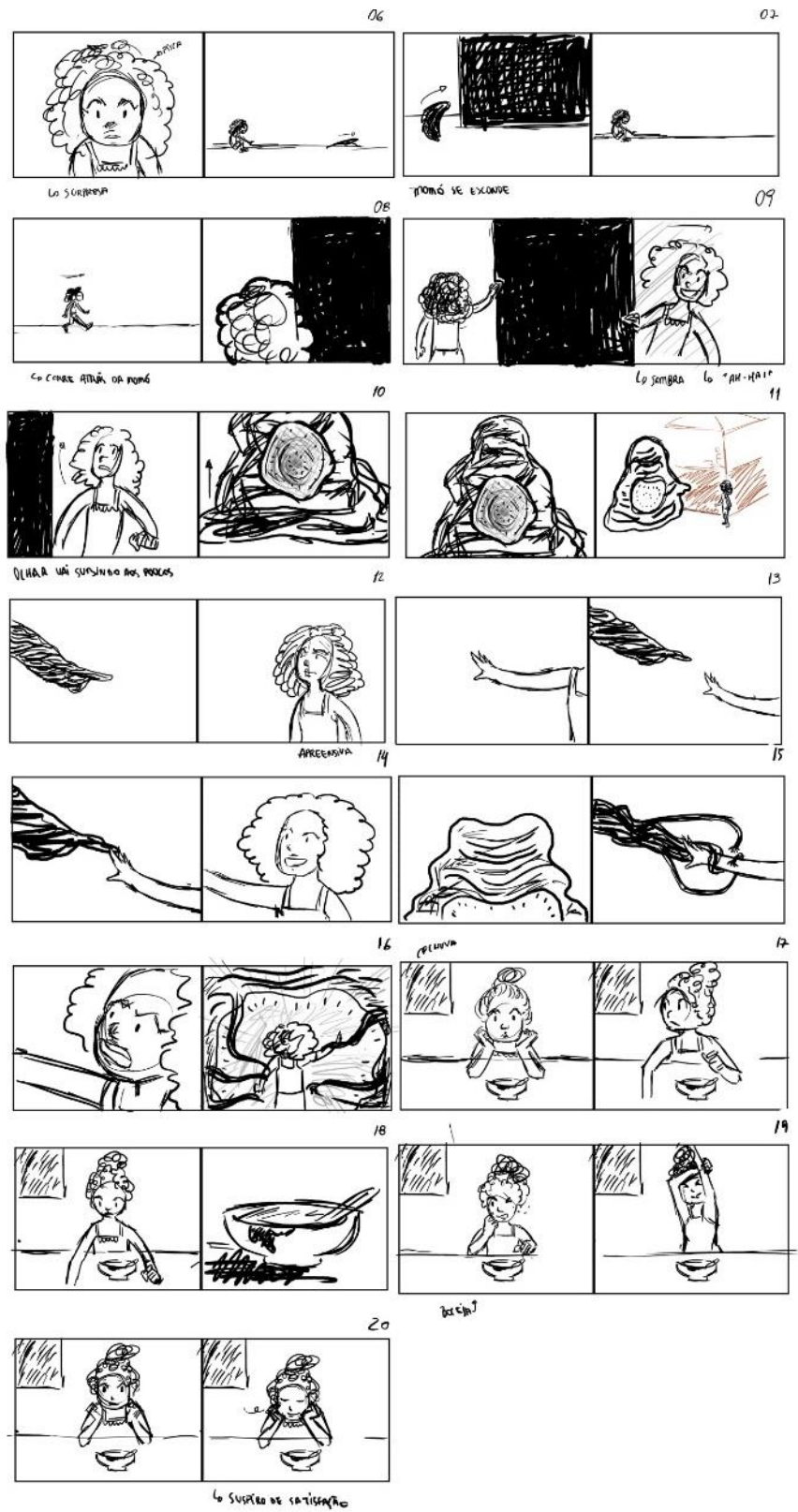

Fonte: A autora (2017).

Assim, após a finalização do storyboard, passou-se para o animatic (ou story reel), para acertar o tempo de cada cena. Para isso, foi utilizado o programa adobe After Effects. Ao final, o story reel ficou com um tempo total de 1 minuto e 7 segundos.

\subsubsection{Concept art}

Desde o princípio, buscou-se manter uma ligação entre a história e o cenário, que compete a área do design emocional, especificamente o aspecto reflexivo do design que é "a parte contemplativa do cérebro" (NORMAN, 2008, p. 41), no concept art, esta ligação fica mais evidente.

Os primeiros esboços foram da menina, nos quais foram testados formatos de olhos, de 
cabeça, a forma geral do corpo, e cores que poderiam ser utilizadas na pele e roupas. Para a caracterização da personagem, foram testadas as roupas que ela deveria usar, (quais mais iriam transmitir aquilo que realmente é utilizado em Belém-PA). A principal questão considerada foi que Belém (PA) é uma cidade muito quente, portanto, a roupa não deveria ser muito comprida ou "pesada". Foram feitos testes de cabelos, e como o foco da história é a culinária, buscou-se utilizar essa referência na personagem também, deixando-a com a chamada "cara de pupunha" (rosto oleoso), portanto, adicionou-se um brilho à testa (figura 7).

Figura 7: Opções de roupas e cabelo.

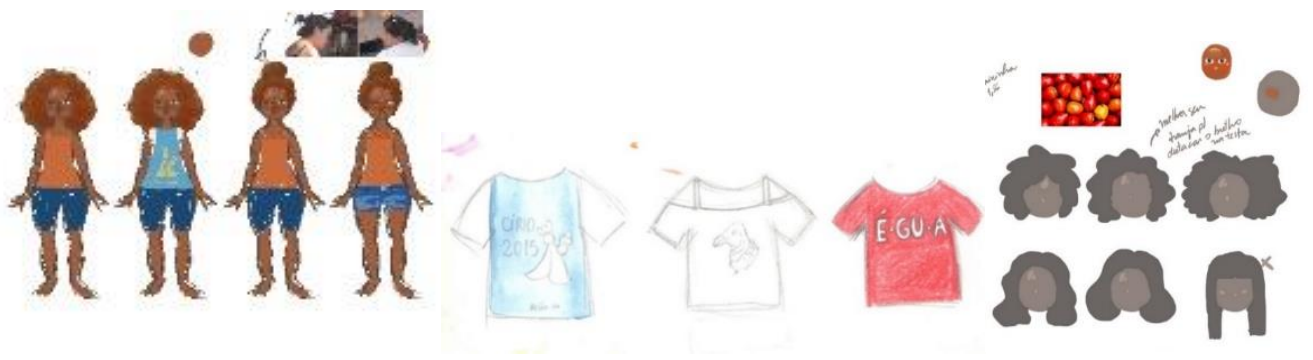

Fonte: A autora (2017).

Devido à complexidade da personagem, e ao nível de dificuldade de animá-la no espaço de tempo disposto, percebeu-se a necessidade de simplificá-la. Essa simplificação (figura 8) ficou como a representação da menina durante o sonho, e quando ela acorda, sua configuração muda para uma mais realista. Foram feitos também testes finais nas cores da camisa, de forma a destacá-la mais, um tipo diferente de cabelo - mais bagunçado, e acrescentou-se uma fitinha, ao pulso direito, como referência à fita do Círio.

Figura 8: Testes finais da personagem no sonho.

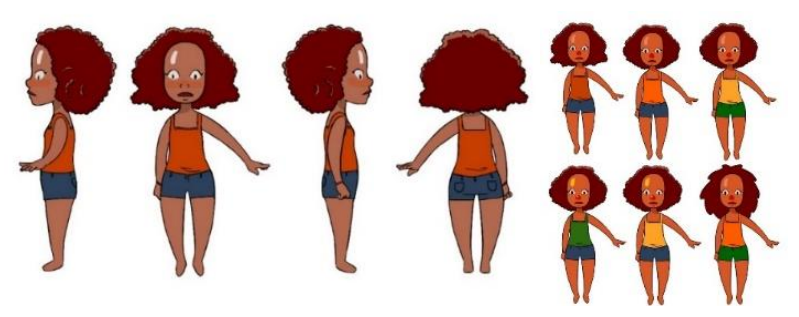

Fonte: A autora (2017).

A Momó foi baseada no açaí, portanto, sua cor assemelha-se ao mesmo. O monstro possui uma forma não uniforme, e orgânica, e sua forma geral é triangular (a base é maior, e vai diminuindo conforme vai subindo). A boca inicialmente possuía formas mais pontudas, com dentes afiados, mas posteriormente optou-se por manter a mesma disformidade na boca (figura 9). 
Figura 9: Esboços da Momó.
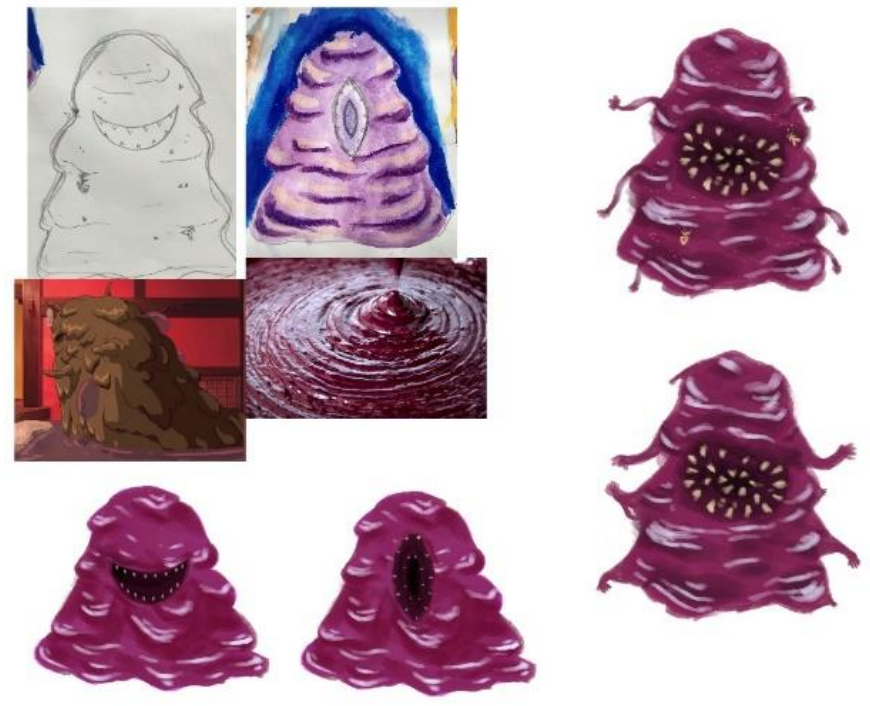

Fonte: A autora (2017).

Os bracinhos da Momó estiveram presentes desde o início da produção, e foram mantidos até o final, com a finalidade de que, no início da história, quando ambos estabelecem contato, a Momó pudesse tocar a menina, conferindo-lhe um aspecto humano e fazendo-a parecer amigável, e no final, quando ela se depara com o monstro da Momó, as mãozinhas conferem um aspecto sinistro e assustador, não mais amigável, e que agarram a protagonista.

Foram feitas, também, representações do Mercado de Ferro, da Praça do Relógio, dos prédios antigos que ficam próximos ao Ver-o-Peso, e das barraquinhas da feira, fora a vegetação, e alguns elementos menores. Que são elementos icônicos ("A ampla expressividade do Ícone decorre da gama de possibilidades interpretativas que ele pode gerar, em especial, de natureza sensorial, estética" [NIEMEYER, 2013, p.40)]), e simbólicos da região. Símbolo, segundo Niemeyer, é:

A associação se dá dentro de um sistema que está subjacente ao signo. [...] Mesmo onde a essência de um Símbolo é a de livre associação, essa associação não é arbitrária, mas determinada por princípios pré-existentes, inerentes ao tipo de código a que pertence o signo. (NIEMEYER, 2013, p.42-43).

Utilizando-se desses conceitos, foram feitos alguns esboços do Mercado de Ferro com formas diferenciadas, mas optou-se por manter sua forma icônica. Os esboços do relógio (da Praça do Relógio), tiveram referência à culinária, em seus ponteiros em formato de garfo e faca. 
Figura 10: Teste de cores e formas no Mercado de Ferro.
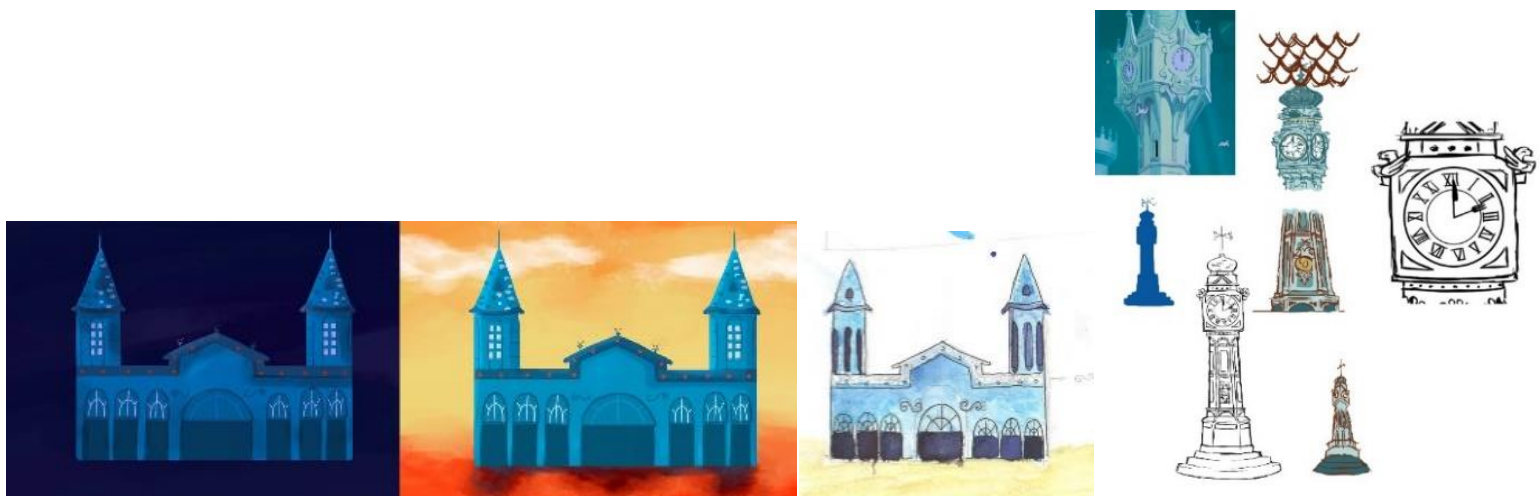

Fonte: A autora (2017).

Quanto aos estabelecimentos do entorno, foram representados pelas construções mostradas na figura 11, que são bastante icônicas no complexo.

Figura 11: Estabelecimentos antigos próximos ao Ver-o-Peso.
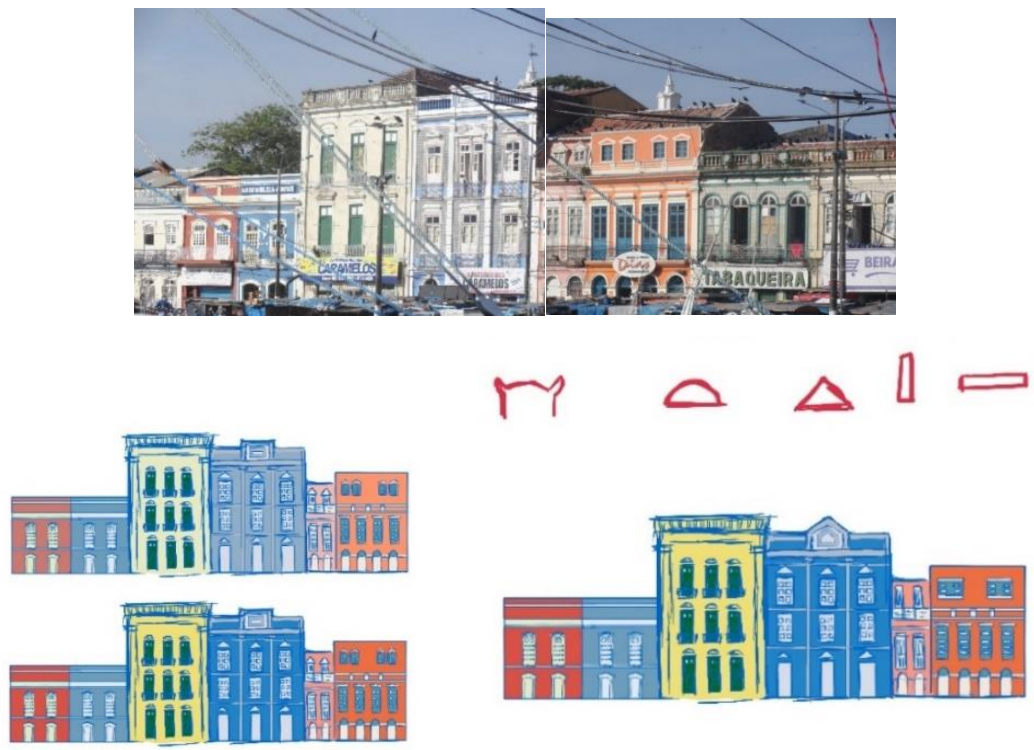

Fonte: A autora (2017).

As barraquinhas do complexo da feira foram reduzidas a três, para demonstrar alguns aspectos importantes para a história. A figura 12 mostra duas possibilidades de barraquinhas: a primeira seria uma de venda de farinha, peixe e camarão. A segunda seria uma de folhas, frutas e cheiros. Manteve-se as barraquinhas nas cores verde, amarelo e rosa, pois em seus produtos predominam essas cores. Para vegetação, foram utilizadas com referência algumas árvores presentes na cidade, em especial a mangueira. A simplificação das folhas foi feita com partes mais escuras e mais claras de verde, com alguns vazados. Na mangueira, os tracinhos são mais alongados, pois as folhas da árvore também o são. 
Figura 12: Barraquinhas da feira.
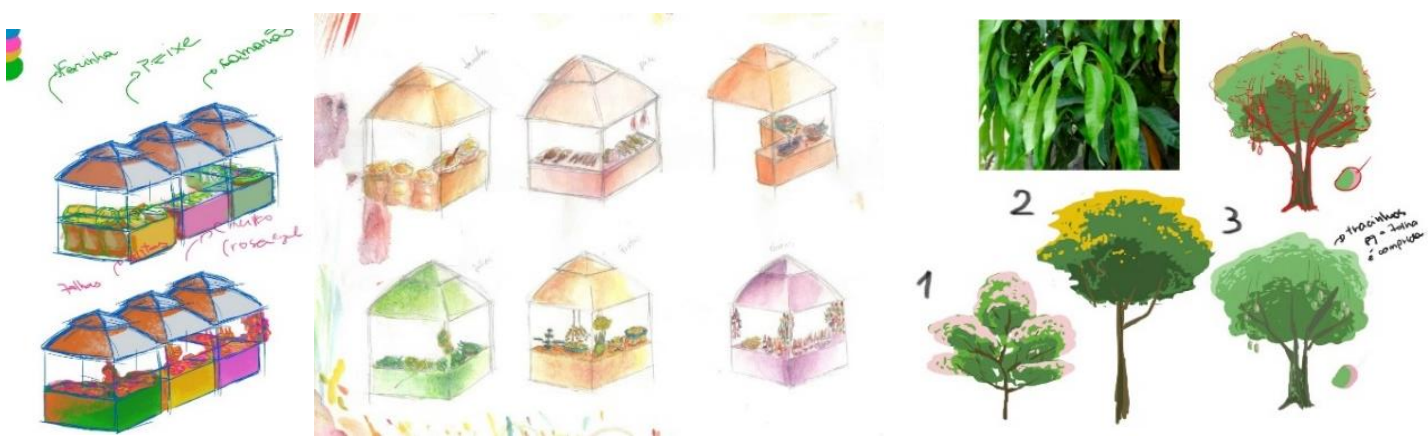

Fonte: A autora (2017)

O cenário no momento que a personagem acorda é em um ambiente fechado, por isso podese trabalhar mais os detalhes internos, como a grade da janela com padrões orgânicos, pela qual passa a luz do sol (figura 13). Foi escolhida uma estética diferente, mais realista, para reforçar a ideia de que a personagem está em outro ambiente.

Figura 13: Momento em que a personagem acorda.

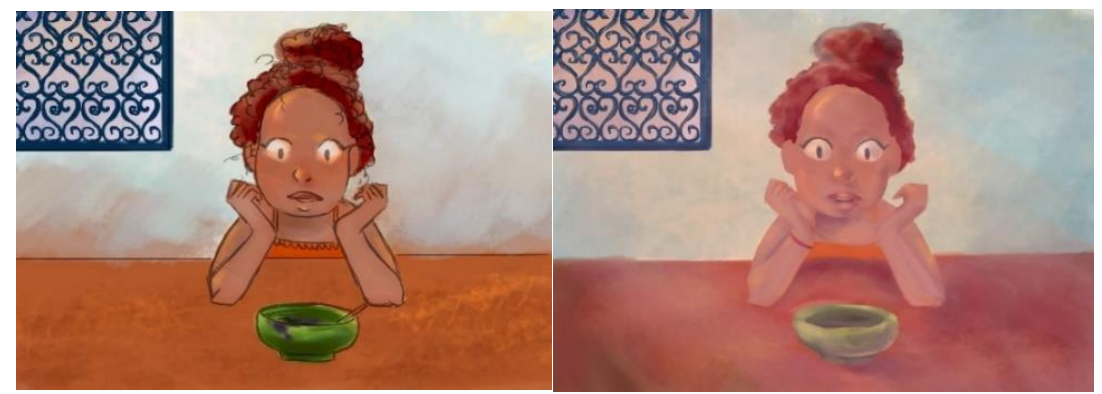

Fonte: A autora (2017).

Para aumentar a ideia de que a personagem comeu muito, e está cheia, por isso "bateu a momó", decidiu-se acrescentar outros elementos à mesa, como restos de comida em um prato, e a farinha para acompanhar o açaí (figura 14). Para deixar os elementos mais próximos - integrá-los no ambiente - utilizou-se grãos de farinha espalhados pela mesa, indicando que a menina a colocou junto com a comida e com o açaí.

Figura 14: Opções de farinheira.

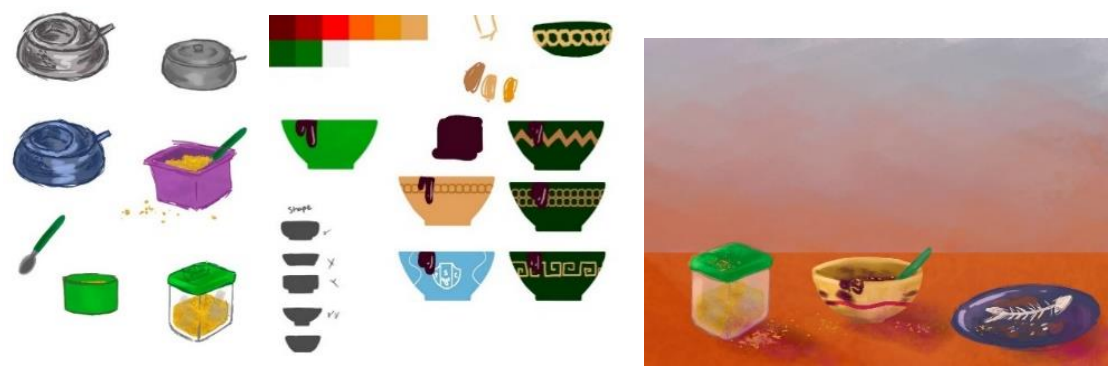

Fonte: A autora (2017). 
Com isso, foram finalizados os testes das personagens e objetos. Passou-se então para a fragmentação do colorscript geral (figura 15).

A cor é a sensação provocada pela ação da luz sobre o órgão da visão (PEDROSA, 2014, p. 20), logo, a cor não é absoluta, ela varia em um objeto, conforme o ambiente em que ele é colocado, e as influências externas que ele sofre para gerar os tons utilizados em cada cenário. Essa variância da cor, foi traduzida em cores mais saturadas no início, para cores menos saturadas no meio, e, na cena final, é retomada novamente um pouco da saturação.

Figura 15: Colorscript completo.

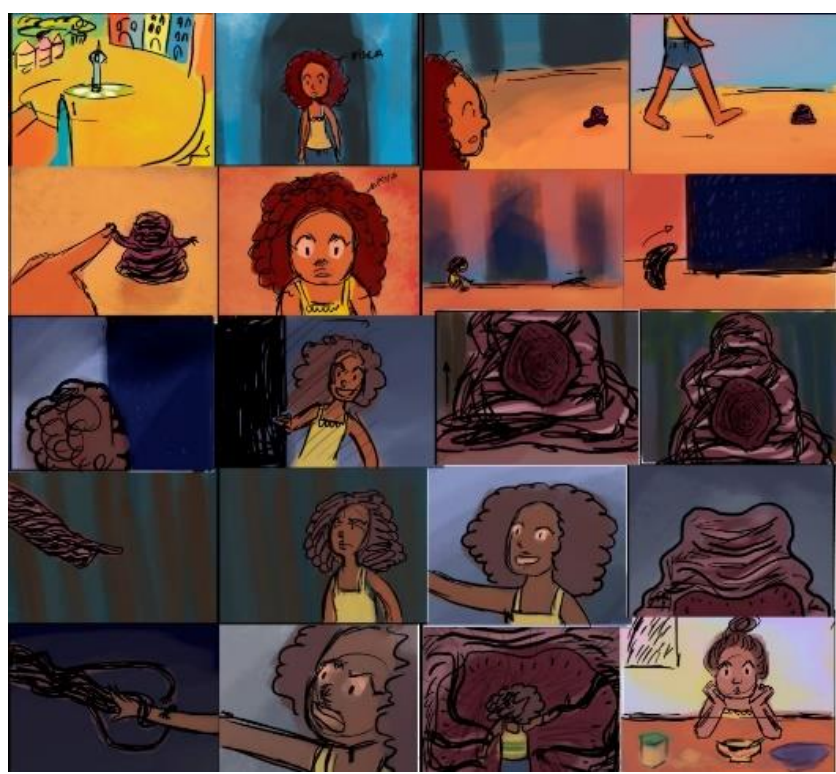

Fonte: A autora (2017).

\subsection{Modelo - Desenhando a personagem.}

Por fim, chegou-se aos concepts finais. A figura 16 mostra o concept da menina durante o sonho, nota-se que a blusa dela foi alterada, optou-se por deixa-la amarela, de forma a chamar mais atenção. Quanto à Momó, houve uma pequena alteração na cor dela, que era mais escura.

Figura 16: Concept final e paleta de cores das personagens.
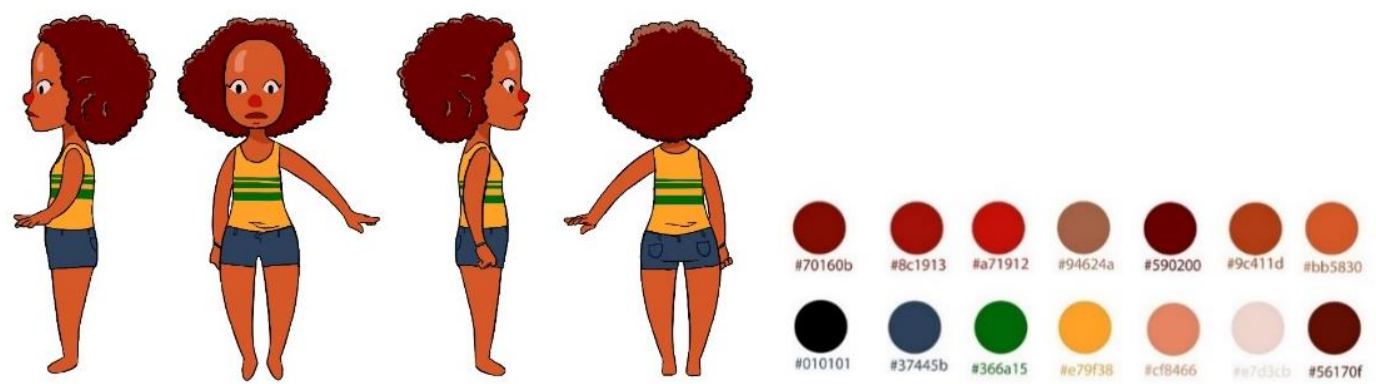

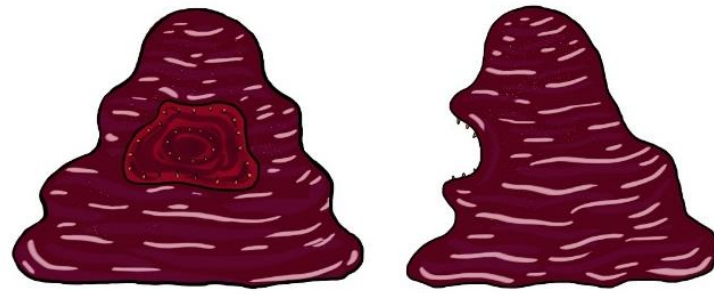

Fonte: A autora (2017).
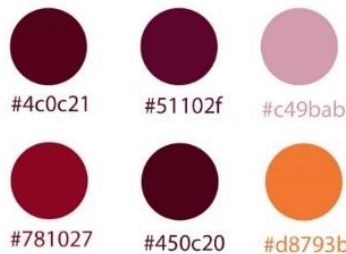

Entre os primeiros e últimos cenários, há algumas diferenças das técnicas utilizadas, no início foi utilizada pintura digital, e quando a menina acorda, foi utilizada aquarela (com apenas alguns retoques no Photoshop). Optou-se por isso para evidenciar a diferença de locais e realidades.

Figura 17: Frames da animação finalizada

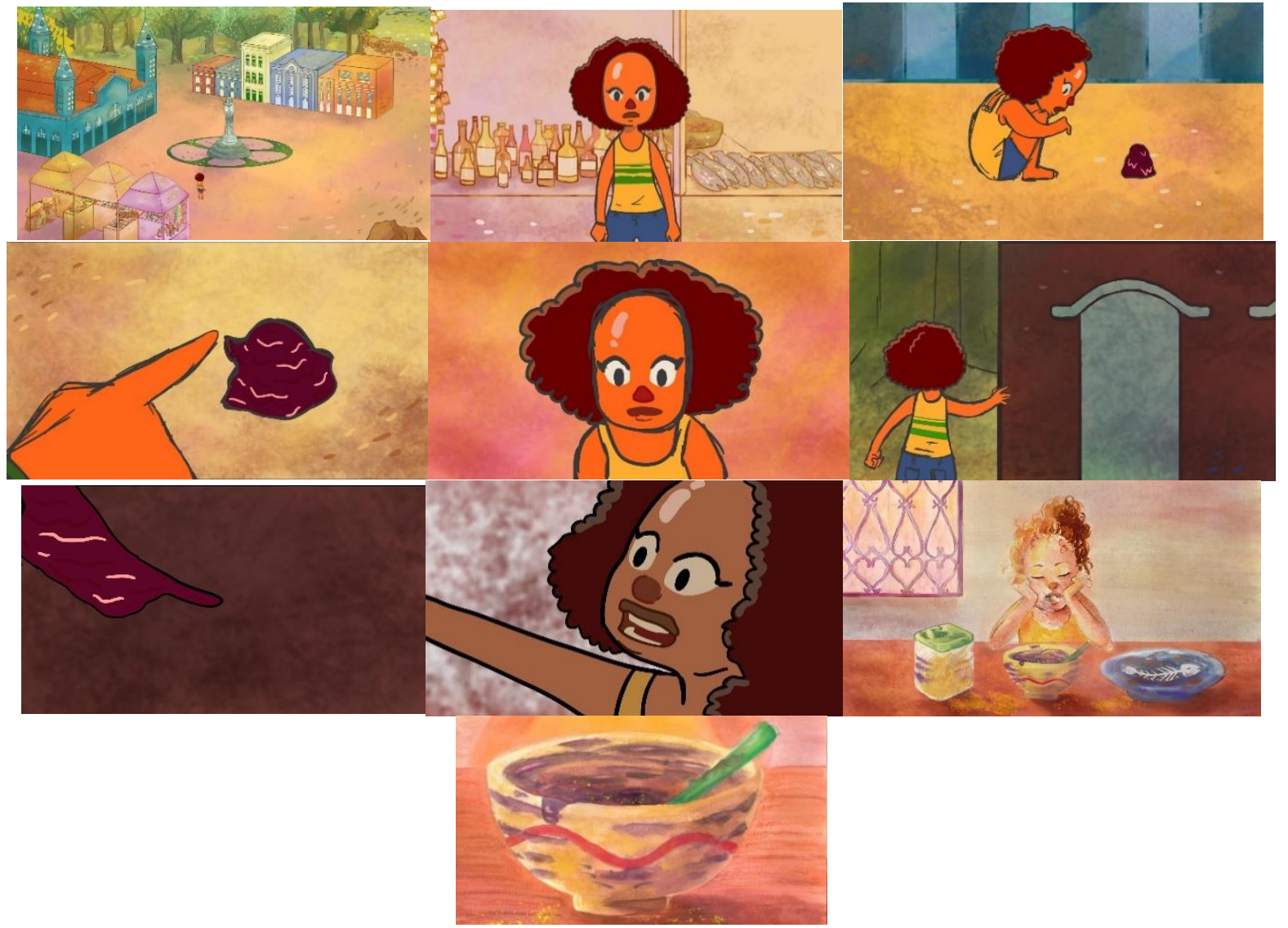

Fonte: A autora (2017).

Os ajustes da pós-produção foram feitos no programa Adobe Première e After Effects, e a trilha sonora utilizada foi composta por Arão Neres de Oliveira Ramos e Aryel Wiron Neres de 
Oliveira Ramos. O curta pode ser visto no link https://vimeo.com/258520114, com a senha: ohmomo.

\section{Considerações finais}

O ponto principal deste trabalho foi incentivar a produção local de animação, e, também mostrar como o design pode contribuir para isso. Ao se passar por todas as etapas e alcançar o resultado, percebeu-se que os objetivos estipulados inicialmente foram alcançados. Foi utilizado o rico cenário de Belém para construir um curta de animação com elementos regionais, foi possível se utilizar das ferramentas do design para otimizar o processo de produção da animação, e agregar mais significado a ela, e alcançou-se um resultado tido como satisfatório. Entretanto, houveram algumas dificuldades, como a estruturação do roteiro, que demorou mais do que havia sido estipulado, pois o resultado esperado, era de uma história que permitisse um grau de fantasia, que foi encaixado na relação da menina com a Momó. Outra dificuldade encontrada foi a realização da animação, que demorou um mês, e alcançou um resultado aquém do esperado.

Apesar das dificuldades, ao final da produção, percebeu-se a viabilidade de se utilizar desse meio de comunicação como um propulsor da cultura belenense, tal qual ocorre com outras regiões no mundo (o próprio EUA que exporta sua cultura em desenhos animados a décadas, ou o Japão com seus animês), e assim começar a delinear um estilo próprio e criar uma tradição de animação em Belém.

Ratifica-se, pois, que a Universidade Estadual do Pará tem muito o que contribuir nesse processo de profissionalização de pessoas para áreas de animação e concept art, principalmente, incluindo disciplinas mais direcionadas para tal. E o mercado mostra essa necessidade de mais profissionais preparados para esse tipo de trabalho, pois é uma área que tende a crescer na região. Destarte, esse trabalho de conclusão de curso mesmo tendo gerado um produto, pode ser ainda muito melhorado, e espera-se que sirva como um referencial e possa incentivar outros alunos a contribuírem com novas ideias e se aventurarem pelo mundo da animação.

\section{Referências}

BEIMAN, Nancy. Prepare to Board- Creating Story and Characters for Animated Features and Shorts. Burlington, Focal Press, 2013.

GIL. Antônio Carlos. Como elaborar um projeto de pesquisa. 4. Ed. São Paulo: Atlas, 2002.

LAKATOS, Eva Maria. MARCONI, Marina de Andrade. Fundamentos da metodologia Científica. 5. Ed. São Paulo: Atlas, 2003.

MUNARI, Bruno. Das coisas nascem coisas. 2. ed. São Paulo: Martin Fontes, 1998.

NIEMEYER, Lucy. Elementos da Semiótica Aplicados ao Design. São Paulo: 2Ab Editora, 2007.

NORMAN, Donald A. Design Emocional - Porque adoramos (ou detestamos) os objetos do dia-a-dia - Rio de Janeiro: Rocco, 2008.

SEEGMILLER, D. Digital Character Painting Using Photoshop CS3. Boston: Charles River Media, 2008. 